\title{
Commentary: Blood from a stone: Should we use low-ejection fraction donors for transplantation?
}

\author{
Kevin Landolfo, MD, ${ }^{\mathrm{a}}$ and Parag Patel, $\mathrm{MD}^{\mathrm{b}}$
}

From the Departments of a Cardiothoracic Surgery and ${ }^{\mathrm{b}}$ Transplantation, Mayo Clinic, Jacksonville, Fla. Disclosures: Authors have nothing to disclose with regard to commercial support.

Received for publication Aug 8, 2018; accepted for publication Aug 10, 2018; available ahead of print Sept 27. 2018.

Address for reprints: Kevin Landolfo, MD, 4500 San Pablo Blvd, Jacksonville, FL 32224 (E-mail: landolfo. kevin@mayo.edu).

J Thorac Cardiovasc Surg 2019;157:1878-9

$0022-5223 / \$ 36.00$

Copyright (C) 2018 Published by Elsevier Inc. on behalf of The American Association for Thoracic Surgery https://doi.org/10.1016/j.jtcvs.2018.08.031

There currently exists a growing disparity between the supply of and demand for donor hearts for transplantation. In addition, donor selection remains imperfect and challenging because of multiple donor, recipient, and institutional factors. One of the most important considerations of potential heart donors relates to the status of the left ventricle $(\mathrm{LV})$. Although both global and regional types of left ventricular LV dysfunction are common after brain death, neither is associated with pathologic changes in the heart. Recovery of LV function in this setting should therefore be expected. ${ }^{1}$ Unfortunately, however, as reported by Tryon and colleagues, ${ }^{2}$ the decision to decline a potential organ continues to be based on donor LV dysfunction alone in $20 \%$ of heart offers. ${ }^{2}$

In the current issue of the Journal, Sibona and colleagues ${ }^{3}$ explore the use of donors with reduced LV function as a way to increase the pool of organs available for transplantation. With data from the United Network for Organ Sharing database between 2000 and 2016, long-term outcomes after transplant of donor hearts with reduced LV function were examined.

The records of more than 31,000 primary isolated heart transplants in patients older than 18 years were reviewed. Patients were divided into 3 groups and analyzed according to donor ejection fraction (EF) by echocardiography (group 1, 20\%-39.9\%; group 2, 40\%-59.9\%; group 3, $\geq 60 \%$ ). Donors with reduced EF were statistically more likely to be younger, male, and with fewer cerebrovascular accidents as mechanism of death compared with normal EF donors. Recipients of the reduced-EF organs were more acutely ill, with higher rates of pretransplant mechanical ventilation and inotropic requirements. Notably, Sibona and colleagues ${ }^{3}$ found no differences in longterm survival, regardless of donor EF. These findings corroborate a recent report of short-term outcomes in a similar population of transplant recipients. ${ }^{4}$ Furthermore, Sibona and colleagues ${ }^{3}$ demonstrate clearly that donor "EF had simply no statistically significant impact on

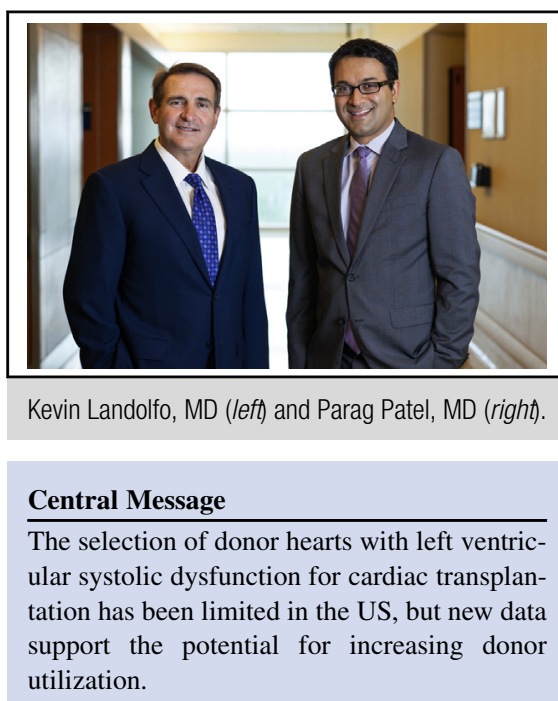

See Article page 1865 . mortality." In addition, normalization of LVEF was seen at one year in the groups with reduced LV function.

Despite innovation in therapies for advanced heart failure, cardiac transplantation remains an important treatment. Inopportunely, transplant rates in the United States have remained static at approximately 2500 cases per year for the past decade. A major factor limiting growth of the heart transplantation rate is the shortage of "acceptable" donor organs, necessitating efforts to safely broaden donor utilization. This study supports the notion that LV systolic dysfunction alone is not an appropriate reason to decline a heart for transplantation-a common occurrence. Increased consideration and use of these reduced-EF donors should be given to patients regardless of the acuity level of the recipient. Sibona and colleagues ${ }^{3}$ suggest that even a conservative use of these donors would potentially increase the US heart transplant rates by more than 700 patients per year. Although increased utilization of reduced-LVEF donors alone is not expected to produce "blood from a stone"to meet the growing need for donor hearts-increased donor utilization is a priority.

\section{References}

1. Goel R, Johnson F, Mehra MR. Brain injury and ventricular dysfunction: insights into reversible heart failure. Congest Heart Fail. 2005;11:99-101.

2. Tryon D, Hasaniya NW, Jabo B, Razzouk AJ, Bailey LL, Rabkin DG. Effect of left ventricular dysfunction on utilization of donor hearts. J Heart Lung Transplant. 2018;37:349-57. 
3. Sibona A, Khush KK, Oyoyo UE, Martens TP, Hasaniya NW, Razzouk AJ, et al. Long-term transplant outcomes of donor hearts with left ventricular dysfunction. $J$ Thorac Cardiovasc Surg. 2019;157:1865-75.
4. Chen CW, Sprys MH, Gaffey AC, Chung JJ, Margulies KB, Acker MA, et al. Low ejection fraction in donor hearts is not directly associated with increased recipient mortality. J Heart Lung Transplant. 2017;36:611-5. 